\title{
Production of biogas at wastewater treatment plants and its further application
}

\author{
Nikolay Makisha ${ }^{*}$ and Daria Semenova ${ }^{1}$ \\ ${ }^{1}$ Moscow state university of civil engineering, Yaroslavskoye shosse, 26, Moscow, Russia, 129337
}

\begin{abstract}
This article covered a wide range of questions on the topic of production and use of biogas as alternative energy source. Biogas is produced by anaerobic digestion of biomass due to the breakdown of fats, proteins and carbohydrates, which constitute the bulk of organic matter. The article describes the most common methods of biogas production, their stages and characteristics. In addition, the article describes some of the possible areas of application of biogas on example of different countries. The article also provides information about key environmental and economic benefits in the case of use of biogas: prevention of methane emissions and lower emissions of carbon monoxide and nitrogen oxides into the atmosphere; the possibility of using secondary raw materials to generate electricity.
\end{abstract}

\section{Introduction}

The most common method of municipal wastewater treatment around the world is mechanical/biological treatment. Modern sewage treatment facilities show highly efficient wastewater treatment, with virtually no impurities. Sewage sludge is formed as resulting by-product purification, to allow its further use as a source of energy and biomass. However, sludge sewage sludge may only be used after proper treatment, which reduces or removes the high water content $(>95 \%)$ load, extraneous contamination, pathogenic bacteria and malodorous substances $[1,2]$.

As an important component to ensure the environmental safety of waste water, modern sludge treatment processes have to meet a number of requirements [3]:

- Effectiveness of capital and operating costs.

- Efficiency of energy use with low consumption and the use of its own reserves.

- Minimal amount of sludge.

- Improvement of the sludge quality. Discharged wastewater that is safe for the environment.

For proper sludge treatment there are two conventional methods of treatment:

- Aerobic sludge stabilization takes place in open sludge tanks with the injection of air. A necessary condition is sufficient volume. Aeration and mixing require a greater energy demand than in the case of anaerobic stabilization [4].

\footnotetext{
*Corresponding author: nmakisha@gmail.com
} 
- Anaerobic stabilization of sludge is the best solution. In respect of costs, efficiency of energy use and environmental protection, anaerobic stabilization of sludge represents the best solution for sewage treatment plants of medium and high capacity. In addition, the combustible gases resulting from controlled fermentation can be used to produce energy.

Depending on the individual requirements of the sewage treatment plant, the optimum result can be achieved also in the dual stabilization, which involves a combination of both processes [5].

\section{Sludge treatment processes}

\subsection{Anaerobic stabilization of sludge. Main advantages}

The growth of energy demand and limitation of $\mathrm{CO}_{2}$ emissions are global problems that require a prompt solution. And if sludge would be stored in landfills, it would have exacerbated the greenhouse effect, as the contaminating gas from the decomposition of waste that was thrown would be in the atmosphere for decades. And above all, emissions of methane, a particularly harmful impact on the environment, as methane is 25 times more active as greenhouse gas than carbon dioxide.

Anaerobic sludge treatment offers an alternative solution with a number of environmental and economic benefits [6]:

- Reduction of organic content at approx. 50\%, and its processing into combustible biogas.

- Production of renewable energy.

- The possibility of independent supply of energy to the sewage treatment plant.

- Lowered production costs.

- Stable and reliable process.

- Reduction of land area taken under construction.

- Reduction in the amount of malodorous substances.

- Sanitary-hygienic measures in relation to sludge (including the reduction of bacteria).

- Climate protection by improving the balance of $\mathrm{CO}_{2}$ emitted and waste treatment facilities.

Anaerobic treatment of precipitation makes a significant contribution to climate protection.

\subsection{Thickening of sludge}

Thickening of sludge before stabilization leads to a significant reduction of its volume, reduction of hydraulic load in the reactor, increase of the gas flow rate and temperature increase of emitted energy [2,7].

Biogas plant is a facility that works on any kind of organic material, the target product of which is biogas. It is currently used or being developed about 60 varieties of biogas technology.

The basis of any biogas is bioreactor. Its construction should meet strict requirements. Thus, the case must be solid at absolute air-tightness of walls. Mandatory good insulation of walls and their ability to reliably resist corrosion. Bioreactor construction should provide possibility of loading and discharging of the reactor and access to its internal space. 


\subsection{Anaerobic digestion of wastewater sludge}

The correct temperature range and optimum retention time of sludge in the reactor are the most important initial factors used in the design of anaerobic stabilization.

Classic stabilization occurs in septic sediment trap, which are a type of bioreactor. After about 20 days, the sludge is subjected to controlled fermentation under vacuum, and the organic matter is recycled into water and biogas. Released thus anaerobic digestion gas (biogas) is a mixture of $50-70 \%$ methane, $30-40 \% \mathrm{CO}_{2}, 0-1 \%$ of steam and trace elements and is combustible and can produce energy $[8,9]$.

Stabilization can occur in different temperature ranges and is carried out in one or two stages. Mainly used mesophilic stabilization at 30-37 C, which takes about 20 days. However, the future for thermophilic stabilization at a temperature of $>53$, which will reduce the period before and at least 15 days.

For optimal process conditions needed to take into account three important factors:

- Sludge mixing by means of a stirrer or pump or injection (bio) gas.

- Avoiding of sludge floating layers.

- Heating of reactors, preferably by the heat of exhaust gases.

\subsection{Dewatering, drying and incineration of wastewater sludge}

During pre-treatment, the residue should be drained to the maximum extent possible. This leads to a further reduction of the sludge volume, thus reducing the load on the subsequent phases of the process. Depending on the characteristics of the precipitation process, stabilized sewage sludge shows the dry matter content of 2-4\%. In General, the stabilization leads to an approximately $30 \%$ reduction in volume of a sludge. Subsequent condensation leads to the increase in the concentration of dry solids up to $4-7 \%$. Subsequent dewatering in centrifuges or filter presses, in sludge waste water to achieve a solids content of $20-35 \%$. With additional drying, for example, in the so-called fluidized bed, the content of dry substances reaches $95 \%$. This gives the possibility of further thermal use of sludge as a supplementary fuel, or in agriculture $[3,10,11]$.

\subsection{Disinfection of wastewater sludge}

Stabilized sewage sludge has a high concentration of nitrogen and phosphorus, which can be used as agricultural fertilizer. But stability, hygiene and transportability of sludge depend entirely on the sanitary safety. In order to reduce the potential impact on the environment, to eliminate health risks and optimize the decomposition there are several additional processes to be used such as heat drying at temperatures $>80 \mathrm{C}$, the water content reduction to lower than $10 \%$, or treatment and a decrease in the content of lime to the $\mathrm{pH}$-value until at least 12 . As a result, accordingly, pathogenic bacteria and viruses are destroyed and inactivated [12].

\section{Biogas application}

Thermal efficiency of gas produced in reactors under anaerobic stabilization is about 6.5 $\mathrm{kWh} /$ cubic $\mathrm{m}$. This corresponds to more than half of the calorific value of natural gas $(\sim 10$ $\mathrm{kWh} /$ cubic meter). If the biogas is used for energy production, the electrical and thermal energy can be used for domestic consumption water treatment facilities and (or) the power electric network: 
- Production of electricity and heat at thermal powerplants: $~ 35-40 \%$ of electricity, about $60 \%$ of thermal energy.

- Direct use in gas engines.

- The use of heat when generating steam or hot water.

Efficient use of biogas can provide the treatment plant with electricity for such purposes as aeration tanks of activated sludge, reactor building heating and hot water, i.e. it is guaranteed independent significant energy savings. Large wastewater treatment plants can cover up to $100 \%$ of their energy requirements through internal generation of electricity [7, 14].

Thus, biogas is a gas produced from organic waste as a result of "methane fermentation". It occurs in the decomposition of organic substances in the result of the activity of two major groups of microorganisms. One group of microorganisms, commonly called acid-forming bacteria or fermentation of microorganisms, breaks down complex organic compounds (proteins, fats and carbohydrates) into more simple, while in the fermentation environment appear primary products of fermentation - volatile fatty acids, lower alcohols, hydrogen, carbon monoxide, acetic and formic acids, etc [15]. These less complex organic substances are a source of food for the second group of bacteria, methaneproducing, which convert organic acids into the desired methane as well as carbon dioxide etc.

Biogas, when treating municipal waste is released during the fermentation of precipitation in the primary clarifiers and excess activated sludge in the digesters at thermophilic mode of its implementation. Biogas at wastewater treatment facilities of Moscow is directed to produce steam in boilers equipped with burners for natural gas and biogas. About $75 \%$ of steam is consumed for heating of digesters, the rest for rooms heating and hot water boilers. Biogas digesters are operated in other cities, but the gas is not used at all or partially recycled. Thus, the domestic scale of efficient operation of these facilities is clearly insufficient [16]. However when the fermentation is only half of the produced sludge allows obtaining 350 million $\mathrm{m}^{3}$ /year of biogas, or 0.3 million tons of conditional fuel by $40-50 \%$ and reducing heat and power costs to the treatment plant as a whole. To reduce costs and to increase the degree of stabilization of sludge and biogas there are two basic methods of intensification of digesters work: increasing the concentration of the load and the biomass of microorganisms [17].

The increase the concentration of load (sediment) can be achieved if to use a gravity thickening, flotation, and centrifugal separation. The increase of biomass concentration of microorganisms in digester can be achieved due to its cultivation with the attachment to fill part of the volume structures of the inert porous media (polyurethane, various types of plastic nets, pipes, expanded clay, etc.). The amount of biomass and its activity in these digesters compared to traditional increases in 2-3 times. Respectively, reduced required duration of fermentation (1-2 days) and the volume of digesters increase the biogas yield. One of the varieties of the intensive process of digestion is the separation of the phases of hydrolysis and methane production (using the principle of attachment of the methane bacteria) $[9,18]$.

The thermal hydrolysis (TG) of wastewater treatment plants sludge developed and operated since 1993 firm "Cambi AS" (Oslo, Norway). The thermal hydrolysis of sludge after dewatering and homogenizing step is achieved by steaming high pressure with subsequent cooling and aging for stabilization. Hydrolysis increases the amount of material available for decomposition of substances for biogas production. After TG, the sediment anaerobic fermented and dried. At the same time its volume is reduced by $50 \%$ compared to the original, the yield of methane increases two times compared to traditional fermentation. The plant capacity is 4 thousand tons/year on dry matter. In the UK, sludge is processed by steaming with a temperature of $160-180^{\circ} \mathrm{C}$ and pressure of 6.3 to $10.2 \mathrm{~kg} / \mathrm{cm}^{2}$, is then sent 
to anaerobic digestion. The performance of the latter increases in two, and the output of biogas three times. The solid content in the sludge increases from 6 to $12 \%$. Modern technology aeration plants provide heat of anaerobic digestion process of sludge $[11,12$, 19].

Modern technology aeration plants provide heat of anaerobic digestion process of sludge. So, on Kuryanovo WWTP (Moscow) spiral heat exchanger (rolled fire hose with a diameter of $10.9 \mathrm{~m}$ ) set in a separate building. It consists of two blocks of dual-channel spiral with a total length of $630 \mathrm{~m}$, which is moving countercurrent hot (fermented) and cold (heated) precipitation. The temperature of the latter on the inlet of the heat exchanger equal to $20-26^{\circ} \mathrm{C}$, at the $38-40^{\circ} \mathrm{C}$ at a temperature of digested slurry after exit from the apparatus 32 to $34^{\circ} \mathrm{C}$. Preheated residue is sent to fermentation. Recent studies showed that biogas from digesters along with the target combustible components (methane and other hydrocarbons) into a number of strong pollutants of the environment. So, at mesophilic/thermophilic fermentation of sludge at the stations of biological treatment of municipal $(60 \%)$ and industrial wastewater there were revealed $1-100 \mu \mathrm{g} / \mathrm{m}^{3}$ of arsenic and antimony, at $10-1000 \mathrm{mg} / \mathrm{m}^{3}$ of mercury, tellurium, lead, tin in the analyzed gas-phase samples. These metals are mainly represented by di-, tri - and tetra - methylated compounds, typical of the process of decay of organic matter. Detected concentrations repeatedly exceeded maximum permissible concentrations (MPC) of compounds of interest. In particular, in Russia, the MPC of mercury, tellurium, lead and tin are in the order of $0.0003-0,05 \mathrm{mg} / \mathrm{m}^{3}$. According to national studies, the nature of contamination is determined by the presence of ammonia and hydrogen sulfide. Their concentration during adverse weather conditions are recorded at a distance of $300-500 \mathrm{~m}$ from the aeration station and $500 \mathrm{~m}$ of sludge drying beds. The obtained results call for a rethinking of the conditions of biogas utilization as a renewable fuel. Treatment of precipitation in the digesters determines the periodic removal of the fermented mass and adherent sludge with the purpose of depositing or disposal. In this regard, there is a need to stop further gas formation, or the location of the precipitation in the city dump will cause serious problems $[20]$.

\section{Conclusions}

Summing up, consider the pros and cons of the use and production of biogas. The undoubted advantages of biofuels obtained by means of recycling is its accessibility, especially for rural residents who can organize a closed production cycle on the farm.

Another advantage of biogas is rich in practically exhaustible, self-replenishing raw materials. Thanks to the "omnivorous" biogas plant can be effectively used in large megacity areas, as additional source of energy in combined environmentally friendly systems for the production of renewable energy, as well as in small rural farms, covering almost all of its needs for mineral fertilizers. Another definite plus is that the biogas plant offers one of the most viable answers to the question, who are increasingly concerned about the ecologists: what to do with the trash? The processing of organic waste into highly effective fertilizer, obtaining as by-products of bio-fuel, valuable in the economy of carbon dioxide, as well as at the equipment installation of special filters, clean water, make biogas plants, in fact, out of competition, compared to other units of waste disposal. It is also worth noting that the construction of a biogas plant processing waste on an industrial scale is not too expensive, and combining it with other sources of renewable energy such as wind and solar, increases the efficiency of the equipment for fermentation of biomass almost several times.

Environmental benefits from the production of biogas is enormous: 
- Reduction of the emission of methane (a greenhouse gas) resulting from the storage of manure under the open sky;

- Reduction of emissions of carbon dioxide and combustion products: charcoal, firewood and other fuels;

- Reduction of air pollution from nitrogen compounds, have an unpleasant odor;

- Reduction of water pollution manure drains;

- Save the forest from logging;

- Reducing the use of chemical fertilizers;

There are advantages and disadvantages that science has yet to overcome. As not ecofriendly biogas, but this fuel does not completely rule out the greenhouse effect. Burning of biogas at least and minimizes harmful emissions but not eliminate them completely. The second problem of biogas, it is available only in rural areas rich in raw materials for production. This problem is rather of organizational and with proper development of infrastructure will be solved by itself, but while the biogas plant remains more of an exception and not an everyday norm, the problem of poor development of the industrial complex is quite acute. Though installation is relatively not expensive, small and individual biogas plants, still expensive for an ordinary farmer, so to buy them you have to take loans in banks. With the aim of faster to repay the loan and to recoup the investment, farmers are starting to grow energy crops, which in turn, again has a negative impact on the earth's environment. The technology for producing biogas is still not perfect, but still have significant pluses for future. Eliminating defects, reducing costs and increasing production efficiency, biogas, and a biogas plant will play an important role in the normalization of the worsening of the ecological situation on the planet.

\section{References}

1. A.G. Pervov, A.P. Andrianov, T.P. Gorbunova, A.S. Bagdasaryan, Petr. Chem., 55(10), 879-886 (2015)

2. Gulshin, A. Kuzina, IJAER, 10, 21, 42618-42623 (2015)

3. E.S. Gogina, O.V. Yantsen, O.A. Ruzhitskaya, AMM, 580-583, 2354-2357 (2014)

4. Volkov, V. Chulkov, R. Kazaryan, M. Fachratov, O. Kyzina, R. Gazaryan, AMM, 580-583, 2281-2284, (2014)

5. A.G. Pervov, A.P. Andrianov, E.B. Yurchevskiy, Petr. Chem., 55 (10), 871-878 (2015)

6. E. Gogina, A. Pelipenko, MATECCONF, 73, 03007 (2016)

7. V.N. Varapaev, S.A. Doroshenko, A.Y. Trotsko, A.V. Doroshenko, IJAER, 10, 21, 42588-42592 (2015)

8. O. Kuzina, E. Pankratov, V. Tkachev, MATECCONF, 86, 05023 (2016)

9. V. Orlov, A. Andrianov, AMM, 580-583, 2398-2402 (2014)

10. V.N. Varapaev, A.V. Doroshenko, I.Y. Lantsova, Pr. Eng., 153, 816-823 (2016)

11. E.S. Gogina, O.A. Ruzhitskaya, O.V. Yantsen. AMR, 919-921, 2145-2148 (2014)

12. N. Makisha, E3sconf, 6, 01002 (2016)

13. A.G. Pervov, A.P. Andrianov, DWT, 35 (1-3), 2-9 (2011)

14. E. Gogina, I. Gulshin, AMM, 580-583, 2367-2369 (2014)

15. Volkov, O. Kuzina, Pr. Eng., 153, 838-843 (2016)

16. N. Makisha, Pr. Eng., 165, 1087-1091 (2016) 
17. A.A. Volkov, A.V. Sedov, P.D. Chelyshkov, D.A. Lysenko, A.V. Doroshenko, IJAER, 10, 22, 43269-43272 (2015)

18. N. Makisha, Pr. Eng., 165, 1092-1097 (2016)

19. E. Gogina, I. Gulshin, Pr. Eng., 153, 189-194 (2016)

20. A.G. Pervov, A.P. Andrianov, V.A. Chukhin, R.V. Efremov, IJAER, 10, 22, 43517 43525 (2015) 